\title{
THE CYANOGENIC GLYCOSIDE AMYGDALIN DOES NOT DETER CONSUMPTION OF RIPE FRUIT BY CEDAR WAXWINGS
}

\author{
Heather M. StruempF, ${ }^{1}$ Jorge E. Schondube, ${ }^{2}$ and Carlos Martínez del Rio ${ }^{2,3}$ \\ 'Department of Zoology and Physiology, University of Wyoming, Laramie, Wyoming 82071, USA; and \\ ${ }^{2}$ Department of Ecology and Evolutionary Biology, University of Arizona, Tucson, Arizona 85721, USA
}

\begin{abstract}
Cyanogenic glycosides are common secondary compounds in ripe fruits that are dispersed by birds. These substances are toxic to some mammals. We examined the repellent effect of amygdalin, a cyanogenic glycoside, on Cedar Waxwings (Bombycilla cedrorum). Amygdalin did not reduce food ingestion in Cedar Waxwings, even at relatively high concentrations. In addition, these birds did not exhibit preference for amygdalin-free over amygdalin-containing fruit. Cedar Waxwings given artificial food that contained four times the amount of amygdalin found in some wild fruits ingested the equivalent of 5.5 times the oral lethal dose for rats in $4 \mathrm{~h}$ without exhibiting any external signs of toxicity. Amygdalin ingestion appeared to have a negative effect on nitrogen retention and food assimilation. However, when nitrogen retention and food assimilation were recalculated assuming that all amygdalin ingested was excreted intact, these negative effects disappeared. The presence of large amounts of unhydrolyzed amygdalin in the excreta of waxwings fed on amygdalinlaced food confirmed our conjecture that amygdalin was excreted intact. We hypothesize that in Cedar Waxwings, amygdalin is absorbed in the intestine but is not hydrolyzed by endogenous enzymes and thus is excreted intact in urine. The apparent lack of repellent effects of amygdalin in Cedar Waxwings suggest that toxicity data for rats and humans may be a poor predictor for the deterrent effect of fruit secondary compounds on frugivorous birds. Many hypotheses that have been posed to explain the presence of secondary compounds in ripe fruit assume that these substances have repellent/toxic effects on avian seed dispersers. For some compounds, such as amygdalin and other cyanogenic glycosides, this assumption may not be valid. Received 6 May 1998, accepted 4 January 1999.
\end{abstract}

RESEARCH ON THE INTERACTIONS between fruit-eating birds and plants has emphasized traits that serve as seed-disperser attractants. The ecological and evolutionary correlates of fruit color (Willson et al. 1990) and nutrient composition (Martínez del Rio 1994) have received considerable attention. The traits that serve to attract avian seed dispersers, however, also can serve to attract fruit parasites that consume and destroy fruit without achieving seed dispersal (Cipollini and Levey 1997a). It has been hypothesized that the secondary compounds often found in ripe fruit serve to deter fruit consumers that do not disperse seeds, such as insects, fungi, and terrestrial vertebrates (Janzen 1977). These observations point to a paradox: how can plants attract some organisms while deterring others?

Cipollini and Levey (1997a) assembled a set of hypotheses that can help to explain this apparent paradox. They recognized that not all

${ }^{3}$ Address correspondence to this author. E-mail: cdelrio@u.arizona.edu secondary compounds are toxic to seed dispersers and that some may even provide foraging cues (the attraction/association hypothesis). However, several of Cipollini and Levey's (1997a) hypotheses assume that secondary compounds in fruit have negative effects on seed dispersers. These negative effects can result from toxicity (the attraction/ repulsion hypothesis), from a reduction in protein assimilation (the protein-assimilation hypothesis), or from laxative or constipative effects (the gut retention-time hypothesis). A common feature of these hypotheses is that the negative physiological effects of plant secondary compounds on seed dispersers benefit plants through increased dispersal and/or germination (see Cipollini and Levey 1997a). In addition, one of $\mathrm{Ci}$ pollini and Levey's hypotheses suggests that some compounds act in a selective fashion.

Their "directed toxicity" hypothesis postulates the existence of secondary compounds in ripe fruit that deter some animals (fruit parasites, presumably) but either attract or have no toxic effect on others (mutualistic seed dispers- 
ers, presumably). This hypothesis assumes that compounds in fruit can have contrasting effects among consumers. Because secondary compounds in ripe fruit are very diverse, evidence in favor of (or against) these hypotheses has been largely indirect. Only Cipollini and Levey's $(1997 b, c)$ work on glycoalkaloids and Cipollini and Stiles (1993) research on the phenolics of ericaceous fruits have explored the effects of a group of plant secondary chemicals on a diverse group of fruit consumers.

Our study focuses on amygdalin, a cyanogenic glycoside found in fruits of the Rosaceae and Caprifoliaceae (Jensen and Nielsen 1973, Majak et al. 1981, Swain et al. 1992). Although cyanogenic glycosides appear to be ubiquitous in ripe fruits (Davis 1991, Barnea et al. 1993), their effect on the avian seed dispersers that consume these fruits are unknown. Excessive ingestion of cyanogenic glycoside-containing food can have severe toxic consequences for some mammals (Newton et al. 1981). Yet, birds can consume prodigious amounts of fruits containing cyanogenic glycosides. For example, Sambucus nigra contains several cyanogenic glycosides with potentially toxic effects to fruit consumers, including humans (Pogorzelski 1982, McGuffin et al. 1997). However, crude extracts from Sambucus fruits appear to stimulate fruit consumption and to promote mass gain in Garden Warblers (Sylvia borin; Bairlein 1996). Although many cyanogenic glycosides have been identified in fruit pulp, we used amygdalin as a "model cyanogenic glycoside" because it is readily available in pure form off the shelf and because its effects on mammals have been relatively well investigated (Newton et al. 1981).

Cyanogenic glycosides are toxic to consumers through two possible mechanisms. In some plant tissues (i.e. seeds of Rosaceae), cyanogenic glycosides and the enzymes that are responsible for their hydrolysis are present in different cell and/or tissue compartments (Poulton and Li 1994). Tissue damage by consumers leads to mixing of cyanogenic substrates with these enzymes and to the release of cyanide (Poulton 1990, Zheng and Poulton 1995). Ingestion of unhydrolyzed cyanogenic glycosides, however, can result in cyanide poisoning when these substances are hydrolyzed by $\beta$ glucosidases of the consumer or of its gastrointestinal microbes (Basu 1983, Adewusi and
Oke 1985, Frakes and Sharma 1986, Gopolan et al. 1992).

Cyanogenesis resulting from tissue damage does not seem to occur in ripe fruit. Fruit pulp that contains cyanogenic glycosides can lack hydrolytic enzymes that produce cyanogenesis (Frehner et al. 1990). Studies have shown that a fraction of the cyanogenic glycosides amygdalin and prunasin is transported intact in intestines of guinea pigs, hamsters, and rats and is hydrolyzed by their livers (Gopolan et al. 1992). Because hydrolysis in the liver after intestinal absorption results in cyanogenesis, ingestion of unhydrolyzed cyanogenic glycosides can produce toxic effects.

We investigated whether amygdalin deters fruit consumption in a highly frugivorous North American bird, the Cedar Waxwing (Bombycilla cedrorum). Cedar Waxwings ingest large amounts of fruits that contain cyanogenic glycosides such as cherries (Prumus spp.) and elderberries (Sambucus spp; Witmer 1996). To explore the deterrent effect of amygdalin, we exposed birds to artificial fruits containing various levels of this substance and measured whether its presence resulted in reduced fruit consumption. To determine whether amygdalin reduces the relative attractiveness of fruit, we offered Cedar Waxwings a choice between artificial fruits with and without amygdalin. We found that even at high concentrations, amygdalin had no deterrent effect on Cedar Waxwings and did not reduce fruit attractiveness.

Ingestion of plant secondary compounds can lead to serious energetic costs and can affect nitrogen balance (Guglielmo et al. 1996). Animals detoxify cyanide via several mechanisms. Some animals use the enzyme rhodanase to convert cyanide into thiocyanate (Way 1984). This mechanism is facilitated by the presence of thiosulfate, which is synthesized from by-products of sulphur amino acid catabolism (Davis et al. 1988). Thus, even if animals are capable of detoxifying cyanide from cyanogenic glycosides, detoxification can have a negative effect on energy and nitrogen balance. To investigate this possibility, we measured the effects of amygdalin in fruit on the nitrogen balance of Cedar Waxwings.

\section{METH(O)S}

Experiments were done on 12 (3 males, 9 females) adult waxwings (body mass, $\bar{x}=34.5=5 \mathrm{D}$ of $1.3 \mathrm{~g}$ ). 
TABLE 1. Composition of amygdalin-free artificial food fed to Cedar Waxwings. Diet components were reagent grade (Sigma, St. Louis). The four levels of amygdalin content used in our experiments were made by adding $114,228,914$, and $1,828 \mathrm{mg}$ of this substance to $100 \mathrm{~g}$ of the mix.

\begin{tabular}{lc}
\hline \hline \multicolumn{1}{c}{ Component } & $\begin{array}{c}\text { Concentration } \\
\text { (g per } 100 \mathrm{~g} \\
\text { wet fruit) }\end{array}$ \\
\hline Agar & 1.33 \\
Casein & 0.64 \\
Fructose & 6.90 \\
Glucose & 6.90 \\
Olive oil & 0.64 \\
Starch & 0.64 \\
Sodium chloride & 0.12 \\
Dicalcium phosphate & 0.12 \\
Vitamin mix & 0.12 \\
Water & 83.90 \\
\hline
\end{tabular}

- Avitron.

Birds were housed individually in stainless steel cages (front, $0.3 \times 0.5 \mathrm{~m}$; back, $0.5 \times 0.5 \mathrm{~m}$ ). Temperature $\left(24^{\circ} \mathrm{C}\right)$ and photoperiod (12L:12D) were maintained constant. Birds were fed a banana-based synthetic maintenance diet (Denslow et al. 1987) ad lit bitum, and water was available at all times. For experiments, we offered birds artificial agar fruits with nutrient composition that mimicked that of ripe fruit pulp (Witmer 1998; Table 1). Briefly, agar and nutrients were added to boiling water and the resulting mixture was spread in shallow trays and refrigerated $\left(4^{\circ} \mathrm{C}\right)$. Cubes $(\mathrm{ca} .0 .5 \times 0.5 \times 0.5 \mathrm{~cm})$ were cut from the trays after the nutrient-agar mixture solidified. Waxwings maintain body mass when fed ad libitum on this artificial diet.

We conducted two experiments to examine the eftects of amygdalin on fruit consumption and acceptability. We compared consumption of amygdalin-free artificial fruits with consumption of fruits containing increasing levels of amygdalin in nochoice tests (Experiment 1). We also examined the preference of birds for amygdalin-free over amygdalin-laced food. Amygdalin (Sigma, St. Louis) was added to the agar-nutrient mixture before mixing with boiling water. Because amygdalin is very resis. tant to heat (Rahway 1989), exposure to boiling water does not affect its toxicity.

Experiment 1.-Birds were fasted overnight and then offered artificial fruit at the onset of the light period. Birds were given amygdalin-free fruit on days 1 and 2 and were offered fruit containing various levels of amygdalin on days 3 and 4 . We used $0.25,0.5,2$, and 4 times the levels found in ripe fruit of Prumus serotina (4.5 mg/g tresh mass; Swain et al. 1992). These four levels spanned from 0.11 to $1.83^{\%} \%$ of the wet mass of the artificial diet (Table 1). Three birds were randomly assigned to each concentration.
Daily trials lasted $4 \mathrm{~h}$, after which food was removed and consumption measured. After $1 \mathrm{~h}$, all excreta produced during the trials were collected and stored frozen at $-20^{\circ} \mathrm{C}$. After excreta were collected, the maintenance diet was given to birds for the remainder of the light period. In this experiment, we expected that birds offered amygdalin-laced food would decrease their consumption relative to control levels. In addition, we expected the birds to show a dose-dependent decrease in intake relative to controls as amygdalin content in food was increased.

Experiment 2.-Our second experiment investigated whether amygdalin reduced the relative acceptability of fruit. We offered birds a paired choice between amygdalin-free artificial fruits and fruits containing four times the level of amygdalin found in wild fruit $(18.3 \mathrm{mg} / \mathrm{g}$ ). We used two food colors that mimicked those found in natural fruits eaten by waxwings (blue and red, McCormic food coloring) to distinguish between food dropped by birds during choice tests. Each bird received two adjacent cups containing blue and red fruit, respectively. Half of the birds received blue-colored fruits laced with amygdalin (red fruit was amygdalin-free), and the other half received red-colored fruits laced with amygdalin (blue fruit was amygdalin-free). The position (e.g. left vs. right) of the amvgdalin-treated diet was switched on day 2. As in the first experiment, trials lasted $4 \mathrm{~h}$. After each trial, food was removed and consumption measured. The banana diet was given to the birds for the remainder of the light period. Preference for amygdalin was measured as the ratio of amygdalin-containing fruit consumed to total food consumption. We estimated preference for or against amygdalin as the ratio of intake of amygdalin-containing fruits to total intake. We tested preference by comparing this ratio to 0.5 , which is the indifference ratio indicating equal consumption of amygdalin-containing and amygdalin-free fruit.

Effects of amygdalin an assinilation and nitrogen balance- - To evaluate the effect of amygdalin on food assimilation, we calculated apparent assimilated mass coefficients $\left(\mathrm{AMC}^{*}\right)$ for the trials of experiment 1 following Karasov (1990):

$\mathrm{AMC}^{*}=($ dry mass ingested - dry mass excreted $) /$ (dry mass ingested)

$\mathrm{AMC}^{*}$ varies from 0 (no assimilation) to 1 (complete assimilation). We examined the effect of amygdalin on nitrogen budgets by regressing nitrogen excretion against nitrogen intake (Robbins 1992). The intercept of this relationship estimates minimum nitrogen excretion for nitrogen-free diets, and the slope is negatively related to the "retention" of nitrogen (Robbins 1992). High values of the slope indicate poor retention of nitrogen, whereas low slopes indicate high nitrogen retention. Amygdalin contains $2.79 \%$ nitrogen by dry mass. Thus, the intercept of nitrogen excretion versus nitrogen intake relationships does not 
vary with amygdalin content in food. To test the effect of amygdalin on nitrogen budgets, we compared among the slopes of nitrogen intake-excretion regressions using analysis of covariance (ANCOVA). These regressions were calculated with a common intercept. Nitrogen determinations were done with an elemental analyzer on finely ground freeze-dried samples.

Our measurements of AMC* and nitrogen balance were conducted over $4 \mathrm{~h}$ rather than $24 \mathrm{~h}$ (Robbins 1992). Thus, they cannot be interpreted as steadystate estimates of assimilation efficiency and nitrogen economy. We use them only as relative indices of the effect of amygdalin on digestive performance and nitrogen requirements. Thiocyanate, the byproduct of cyanide detoxification, contains the same amount of nitrogen as amygdalin per molecule (Majak 1992). The thiocyanate molecule also contains sulphur (Conn 1979). Thus, the detoxification of cyanide and the subsequent excretion of thiocyanate is accompanied by significant excretion of sulphur. To examine the possibility that Cedar Waxwings detoxified cyanide using the thiocyanate pathway, we measured the sulphur concentration in excreta with an elemental analyzer.

Do Cedar Waxwings excrete amygdalin intact?-Data on assimilation efficiency and nitrogen balance suggested that amygdalin was excreted unhydrolyzed by Cedar Waxwings (see below). To test this, we measured amygdalin content in food and in excreta collected in experiment 1 . Amygdalin content was estimated from changes in color in picrate paper after HCN was liberated enzymatically (Woodhead and Bernays 1978). The color of Picrate paper changes from bright yellow to vermillion in the presence of HCN. We made picrate paper strips $(0.5 \times 7 \mathrm{~cm})$ by dipping number 1 Whatman filter paper in a picrate ( 6.5 g per $\mathrm{L}$ ) solution made alkaline with anhydrous $\mathrm{Na}_{2} \mathrm{CO}_{3}(50 \mathrm{~g}$ per $\mathrm{L}$ ). Paper strips were allowed to dry before use. Approximately $200 \mathrm{mg}( \pm 5 \mathrm{mg}$ ) of food or feces were placed in glass culture tubes $(12 \times 75$ $\mathrm{mm}$ ), and HCN from amygdalin was liberated by addition of $1 \mathrm{~mL}$ of emulsin solution $(1 \mathrm{mg} / \mathrm{mL} \beta$-glucosidase) in $0.2 \mathrm{M}$ phosphate buffer $\left(\mathrm{NaH}_{2} \mathrm{PO} 4 /\right.$ $\mathrm{Na}_{2} \mathrm{HPO}_{4}, \mathrm{pH} 7$ ). Tubes were stoppered tightly and incubated for $20 \mathrm{~h}$ at $21^{\circ} \mathrm{C}$. Color was stable after this interval. We estimated amygdalin using a logarithmic scale, with cyanogenic scores ranging from 1 ( $0.625 \mathrm{mg}$ of amygdalin) to 5 (10 mg of amygdalin). Because visual inspection of color in picrate paper is inaccurate, and because color saturates at high cyanide concentrations ( $>0.22$ mmoles), our estimates of amygdalin levels can be used for comparisons among treatments but not for quantitative estimation.

\section{RESLLTS}

Experiment 1.-Because food intake did not differ between days 1 and 2 when birds were

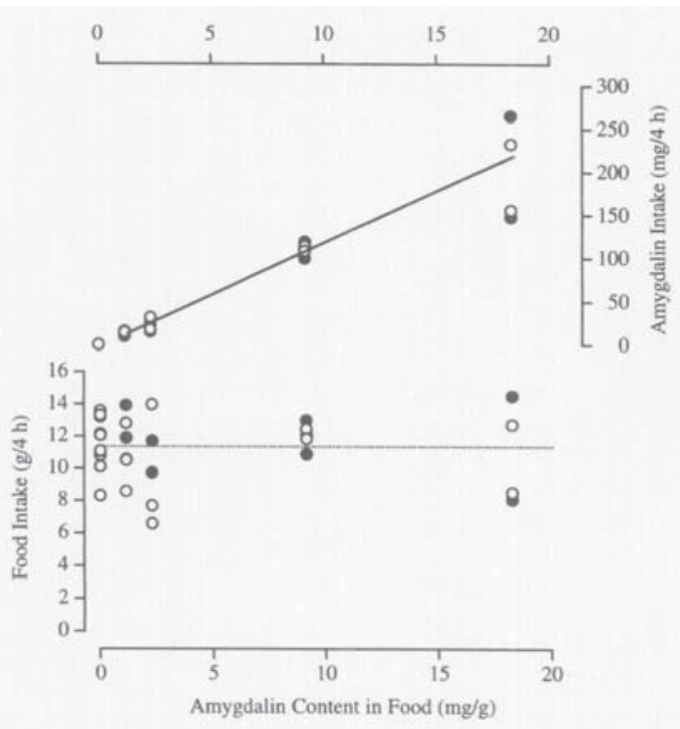

FiG. 1. Lower panel: relationship between food intake and amygdalin content. Dotted line is average intake of amygdalin-free food (10.8 $\pm 2.3 \mathrm{~g}$ per $4 \mathrm{~h}$ ). Note that food consumption did not decrease with amygdalin content. Upper panel: because food intake did not decrease with amygdalin content, amygdalin intake increased linearly $(y=0.001+$ $0.016 x, r=0.96, n=36$ ) with content. Open and closed symbols represent days 3 and 4 of experiment 1 , respectively, except for zero level of amygdalin content in food.

fed amygdalin-free food (paired $t=0.9, P>$ 0.1 ), we used the average of these two days as an estimate of average food consumption. Mean food consumption of birds fed artificial fruits without amygdalin was $10.8 \pm$ SD of 2.3 $\mathrm{g}$ per $4 \mathrm{~h}$. Contrary to our predictions, birds did not exhibit a dose-dependent decrease in food intake when fed artificial fruit with amygdalin (day $3, r_{s}=0.07$; day $4, r_{s}=0.09, P>0.50 ;$ Fig. 1). Because birds did not decrease food consumption as amygdalin concentration in food increased, amygdalin intake increased linearly with increased amygdalin content in food $\left(r^{2}=\right.$ 0.91; Fig. 1). Birds fed a diet of artificial fruit containing the highest amygdalin level (18.28 $\mathrm{mg} / \mathrm{g}$ ) ingested $139.5 \pm 104.5 \mathrm{mg}$ of amygdalin in $4 \mathrm{~h}$. This amount equals approximately five times the $50 \%$ lethal oral dose $\left(\mathrm{LD}_{50}\right)$ for rats ( $800 \mathrm{mg} / \mathrm{kg}$; Adewusi and Oke 1985).

Experiment 2.-Because birds exhibited no difference in preference between days 1 and 2 (paired $t=0.094, P>0.50$ ) we used the average preference in these two days as an estimate of 


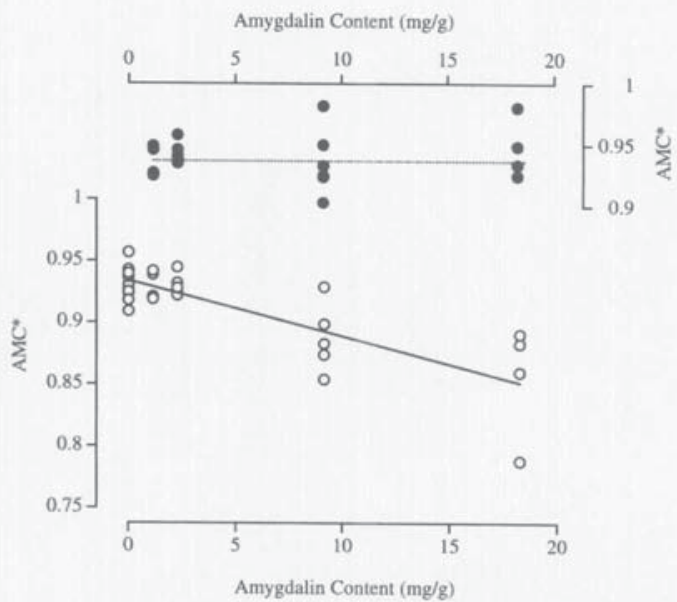

FIG. 2. Lower panel and open symbols: effect of amygdalin on assimilation efficiency as estimated by apparent assimilated mass coefficients $\left(\mathrm{AMC}^{*}\right)$. $\mathrm{AMC}^{*}$ decreased linearly with amygdalin content in food ( $y=0.934-0.005 x, r=0.80, n=36)$. Upper panel and closed symbols: when it is assumed that all the dry mass of amygdalin ingested is excreted intact, $\mathrm{AMC}^{*}$ of the amygdalin-free fraction of food did not decrease with amygdalin content in food and did not differ significantly from $\mathrm{AMC}^{*}$ of amygdalin-free food (stippled line; $\mathrm{AMC}^{*} \pm 0.93=0.13$ ).

preference for amygdalin. The absence of a preference from day 1 to day 2 of this experiment indicates that birds did not show side biases (Jackson et al. 1998). Birds strongly preferred red food (preference $\pm \mathrm{SD}=0.9 \pm 0.2$ ) over blue food $(0.2 \pm 0.4 ; F=18.3, \mathrm{df}=1$ and $11, P<0.01$ ), but exhibited no significant preference for (or against) amygdalin (0.6 $\pm 0.4, t$ $=0.65, P>0.50$ ) .

Effects of amygdalin on assimilation efficiency and nitrogen balance.-Apparent assimilated mass coefficients decreased linearly with increased amygdalin content in food $\left(r^{2}=-0.64\right.$, $P<0.01$; Fig. 2). Amygdalin content had a significant effect on the slope of nitrogen intakeexcretion relationships (ANCOVA on slopes, $F$ $=3.7, \mathrm{df}=4$ and $27, P<0.05 ;$ Fig. 3 ). The slope of the nitrogen intake-excretion regressions increased with increased amygdalin content in food (Fig. 4). Thus, it appeared that amygdalin decreased nitrogen retention in a dose-dependent fashion.

The apparent effect of amygdalin on assimilation efficiency and nitrogen retention must be tempered by two observations: (1) the efficiency with which amygdalin is absorbed by

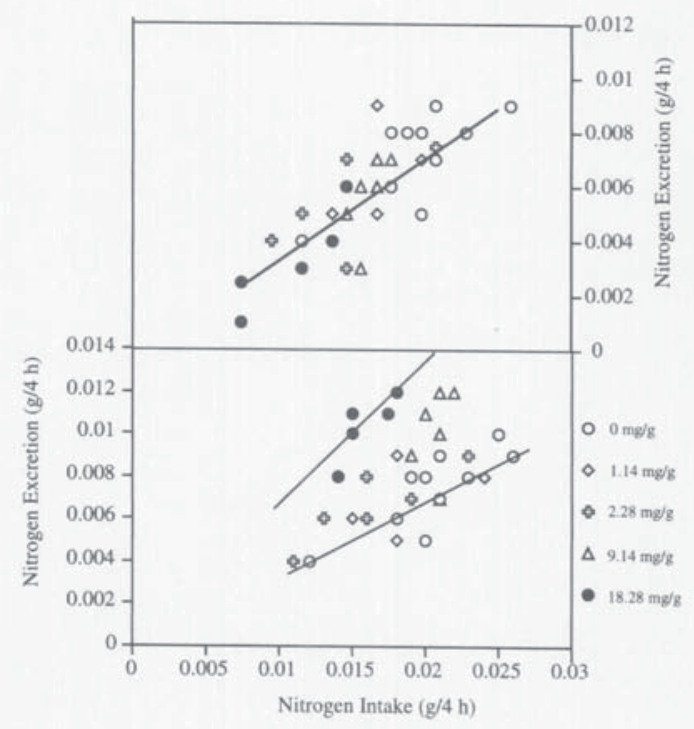

FIG. 3. Lower panel: relationship between nitrogen intake and nitrogen excretion in Cedar Waxwings fed on an artificial diet containing different amygdalin contents. Contents are identified by different symbols. Regression lines were constructed for the two extremes of amygdalin content $(0$ and $18.28 \mathrm{mg} / \mathrm{g}$ ). Upper panel: nitrogen intake-excretion relationship for the amygdalin-free component of diet. This relationship was obtained assuming that all nitrogen ingested in amygdalin is excreted. Note that amygdalin content has the effect of increasing the slope of the nitrogen intake-excretion relationship. When the effect of amygdalin is removed, amygdalin has no significant effect on the nitrogen intake-excretion relationship, and the data are adequately described by a single regression line $(y=$ $0.0005+0.358 x, r=0.72, n=36$ ).

birds is unknown, and (2) amygdalin contains nitrogen. Consequently, it is possible that the effects of amygdalin on assimilation and nitrogen retention simply were the result of amygdalin being excreted intact. If Cedar Waxwings do excrete amygdalin intact, then an increase in the amygdalin content of food would lead to a decrease in both assimilation efficiency and nitrogen retention.

To explore the feasibility of this alternative, we reanalyzed our assimilation and nitrogen balance data, assuming that all of the ingested amygdalin was excreted. When AMC* was recalculated by removing dry mass of amygdalin ingested from intake and excretion, $\mathrm{AMC}^{*}$ did not decrease significantly with amygdalin content in food $\left(r_{s}=0.04, P>0.5\right.$; Fig. 2$)$. In ad- 


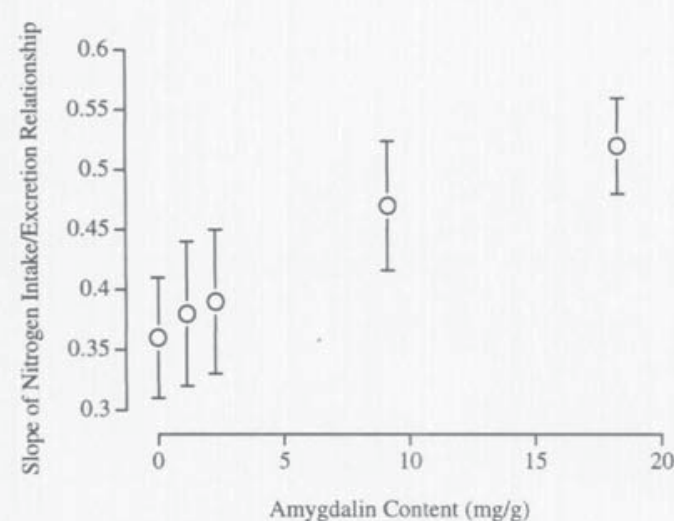

FIG. 4. Relationship between estimated slopes of the nitrogen intake-excretion relationship and amygdalin content in food. Slopes were estimated by ANCOVA on a model with a common intercept. Bars are standard errors.

dition, $\mathrm{AMC}^{*}$ of food with various amygdalin levels did not differ significantly from $\mathrm{AMC}^{*}$ of food with no amygdalin (ANOVA, $F=0.6$, df $=4$ and $31, P>0.50$; rig. 2). A similan resulh was found for protein balance. When we accounted for the contribution of amygdalin's nitrogen to nitrogen intake and excretion, the slopes of the nitrogen intake-excretion relationship did not differ with amygdalin content (ANCOVA on slopes, $F=0.2, \mathrm{df}=4$ and $27, P$ $>0.50$; Fig. 3).

Sulphur excretion. - We found no detectable sulphur in the feces of Cedar Waxwings. Because our instrument was not set up to detect trace amounts of sulphur (less than $100 \mathrm{ppm}$ ), our observations do not prove that no sulphur occurred in excreta. Rather, they indicate that Cedar Waxwings were not excreting the amounts of sulphur expected if they were using the thiocyanate pathway to detoxify cyanide.

Do Cedar Waxwings excrete amygdalin intact?Data on assimilation efficiency and nitrogen balance suggested that amygdalin was excreted unhydrolyzed by Cedar Waxwings. This notion is supported by the presence of large amounts of unhydrolyzed amygdalin in excreta (Fig. 5). Excreta contained significantly more amygdalin than food at all but the highest experimental concentrations (paired $t>4.5, P<$ $0.01, n=5$ ). The lack of a significant difference between food and excreta for food containing high concentrations of amygdalin is the result

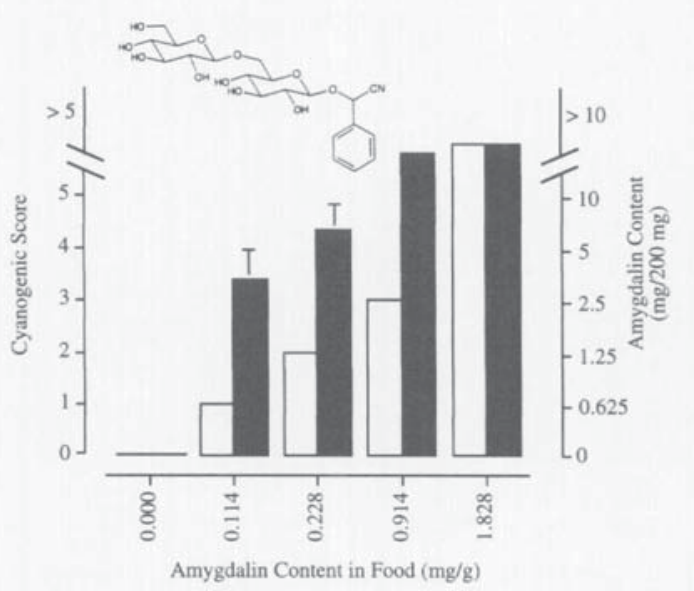

FiG. 5. Average amygdalin content in food (open bars) and excreta (black bars) in Cedar Waxwings fed on an artificial diet laced with different amygdalin contents. The chemical formula represents amygdalin. Bars are standard deviations calculated from cyanogenic scores. Because we estimated amygdalin content using visual scores (left scale), the scale at the right side of the graph should be considered an approximation.

of color saturation in our assay at high concentrations of cyanide.

\section{DisCuSSION}

Amygdalin and food intake.-Amygdalin did not reduce food intake in Cedar Waxwings, and these birds showed no significant aversion for amygdalin-laced relative to amygdalin-free food. Cedar Waxwings ingested the equivalent of five times the oral $L D_{50}$ estimated for rats with no apparent ill effects. Because $\mathrm{LD}_{50}$ is estimated with a single dose, whereas experimental waxwings ingested amygdalin over a 4-h period, our measurements are not strictly comparable to the toxicity of amygdalin estimated for rats. However, this comparison emphasizes the ability of Cedar Waxwings to tolerate high levels of amygdalin without exhibiting external toxic effects. Sublethal doses of amygdalin in rats and humans lead to tremors, motor ataxia, and paralysis (Basu 1983). The lack of acute toxic effects of amygdalin in birds is also demonstrated by the absence of preference of Cedar Waxwings for amygdalin-free over amygdalin-laced fruits. Birds are sensitive to toxic substances and are capable of rapidly developing aversions against substances that 
produce even relatively mild physiological discomfort (Clark et al. 1991).

Amygdalin did not appear to produce any long-term effects on waxwings. Experimental birds maintained body mass and survived in good health for several months after the experiments were conducted. Birds were indifferent to concentrations of amygdalin that were four times higher than those found in wild fruits. Thus, it appears that the amount of amygdalin normally found in wild fruit has no deterrent effect on Cedar Waxwings. The presence of amygdalin in fruit pulp may not reduce fruit consumption in birds, even at relatively high concentrations. The lack of deterrent effects of amygdalin on Cedar Waxwing poses two questions. Why does amygdalin appear to be nontoxic to Cedar Waxwings but toxic to some mammals (e.g. guinea pigs, hamsters, humans, and rats)? What is the biological function, if any, of amygdalin in fruit pulp?

Why is amygdalin nontoxic to Cedar Waxwings? - The ingestion of cyanogenic glycosides can have a toxic effect because their hydrolysis by intestinal microorganisms or endogenous enzymes releases cyanide. Cyanide prevents oxygen utilization by the inhibition of cytochrome oxidases (Majak 1992). If cyanogenic glycosides are not hydrolyzed, their ingestion has minimal or no consequences because they are absorbed, usually with high efficiency in the intestine, and voided intact in urine (Barrett et al. 1977, Majak 1992). The variation in toxicity of ingested cyanogenic glycosides observed among animals can be explained by differences in three processes: (1) the relative importance of fermentative versus non-fermentative processes in digestion; (2) variation in the expression of endogenous $\beta$ glucosidases that are responsible for the release of cyanide; and (3) variation in the ability of animals to detoxify cyanide. Because gut microorganisms possess active $\beta$-glucosidases, ingestion of cyanogenic glycosides appears to have more severe toxic effects on animals with significant fermentative digestion than on nonfermenters (Majak 1991). In non-fermenters, a significant fraction of ingested cyanogenic glycosides can be excreted intact (Barrett et al. 1977). Because fermentative processes play a negligible role in the digestive function of $\mathrm{Ce}$ dar Waxwings, cyanide production in their guts is unlikely.
Cedar Waxwings may not be sensitive to amygdalin because (1) they do not absorb it in the intestine; (2) their levels of endogenous $\beta$ glucosidases are so low that absorbed amygdalin is not hydrolyzed; or (3) they have effective detoxification mechanisms. The absence of an effect of amygdalin on nitrogen balance in Cedar Waxwings does not allow discrimination among these three hypotheses. Quantitative increases in nitrogen excretion can result from the lack of assimilation of amygdalin, from excretion of unhydrolyzed amygdalin, or from excretion of detoxification by-products. Because sulphur excretion in Cedar Waxwings fed amygdalin was negligible, it is unlikely that waxwings used the thiocyanate pathway to detoxify cyanide. When we estimated corrected apparent assimilation efficiency by assuming that all ingested amygdalin was voided, we found that assimilation efficiency of the amygdalin-free fraction of food was not affected by the presence of amygdalin. This observation, and the lack of significant sulphur excretion, suggest that Cedar Waxwings excrete either unassimilated fecal amygdalin or unhydrolyzed urinary amygdalin. Higher amygdalin content in excreta than in food indicates that amygdalin was "concentrated" and thus was retained by Cedar Waxwings with less efficiency than other dietary components. This observation strongly supports the hypothesis that most, if not all, of the ingested amygdalin was excreted intact, either in the urine or in the feces.

Although the uptake mechanism is unknown, vertebrates seem to absorb amygdalin in the intestine with high efficiency (Davis 1991). Variation in expression of endogenous $\beta$ glucosidases and detoxification mechanisms in animals have not been explored systematically, but there appears to be significant interspecific differences even within closely related taxa (Majak 1992). Therefore, we speculate that in Cedar Waxwings, amygdalin is absorbed in the intestine but is not hydrolyzed by endogenous enzymes and thus is excreted intact in urine. One of the traits that seems to increase cyanogenic glycoside tolerance in some insects is the down-regulation of endogenous $\beta$-glucosidases (Ferreira et al. 1997). In a similar fashion, tolerance of Cedar Waxwings for these compounds may be caused by low expression levels of these enzymes. 
What is the biological function of cyanogenic glycosides in fruit pulp?-Amygdalin appears to have no effect on fruit consumption by at least one avian seed disperser. What are the effects of amygdalin and other cyanogenic glycosides on other fruit consumers? Unfortunately, the limited data available do not provide an answer to this question. Cyanogenic glycosides may have antifungal effects (Ito and Kumazawa 1995), but these effects have not been studied systematically. The effects of cyanogenic glycosides on insects vary dramatically among species. For example, amygdalin and linamarin do not appear to have a strong deterrent effect on folivorous orthopterans (Bernays 1983), but they do result in reduced food intake in two noctuid caterpillars (Glendinning and Slansky 1994). More work on the effects of cyanogenic glycosides on fruit microbes and arthropod fruit consumers will be necessary to determine whether these compounds play a deterrent role in these non-mutualistic fruit consumers (Hruska 1988).

In addition to fungi and arthropods, the ranks of seed predators and pulp "thieves" (sensu Levey and Cipollini 1998) also include mammals and birds. Toxicity after ingestion of cyanogenic glycosides has been demonstrated in a few mammals (see Majak 1992). Although some mammals are sensitive to cyanogenic glycosides, we caution against generalizing this observation to all mammals. Fruit containing cyanogenic glycosides can be ingested in large amounts by black bears (Ursus americanus; Martin et al. 1951), and the daily amount of bamboo shoots ingested by golden bamboo lemurs ( $\mathrm{Ha}$ palemur aureus) contains 12 times the lethal cyanide dose calculated for humans and rats (Glander et al. 1989). To our knowledge, no attempt has been made to test the toxicity of these compounds on avian seed predators and pulp "thieves." Consequently, we caution against generalizing the apparent tolerance shown by Cedar Waxwings to all birds. It is possible that significant variation exists in tolerance to cyanogenic glycosides in mammals and birds. In addition, we tested only one cyanogenic glycoside, amygdalin. Many others (e.g. prunasin and sambunigrin) occur in fruit (Pogorzelski 1982, McGuffin et al. 1997). The general mechanism of cyanide release is shared by all of these compounds, but the details of the cyanogenic pathway can differ. Thus, the lack of a toxic effect of amygdalin on Cedar Waxwings should not be interpreted as lack of toxicity of all cyanogenic glycosides to all fruiteating birds.

Although the general applicability of our results to all cyanogenic glycosides and all fruiteating birds has not been established, our results justify a cautionary note. Many phenomenological studies of secondary compounds in fruit assume that these substances have an effect on fruit consumption by avian seed dispersers (e.g. Herrera 1982, Izhaki and Safriel 1989, Barnea et al. 1993). This assumption is justified by toxicity data on model species of mammals. The absence of a deterrent effect of amygdalin on fruit consumption by Cedar Waxwings indicates that toxicity data for rats and humans may be a poor predictor for the deterrent effect of secondary compounds on frugivorous birds. Secondary compounds may be important mediators of interactions in the triad of fruit robbers, fruits, and seed dispersers (Levey and Cipollini 1998), but their biological role cannot be assumed. Rather, it must be established experimentally.

ACKNOWIEDGMENTS

Mark "waxwing" Witmer generously helped us to make artificial fruit and gave us advice on bombycillid care. Doug Levey, Rob Raguso, Rex Sallabanks, Wes Weathers, and two anonymous reviewers made helpful comments on earlier versions of the manuscript. We are particularly thankful for the incisive comments of the anonymous reviewer that sent us back to the bench to assay amygdalin levels in waxwing excreta. Liz Bernays read the manuscript and gave us a cyanogenesis assay recipe. Our work was funded by National Science Foundation grant IBN928505 to C. Martínez del Rio and CONACyT (Mexico) doctoral fellowship 125663 to J. E. Schondube.

\section{Litera ture Cited}

ADEwusl, S. R. A., AND O. L. OKe. 1985. On the metabolism of amygdalin. The $\mathrm{LD}_{5,1}$ and biochemical changes in rats. Canadian Journal of Physiological Pharmacology 63:1080-1087.

BAIRLEIN, F. 1996. Fruit-eating in birds and its nutritional consequences. Comparative Biochemistry and Physiology A 113:215-224.

Barnea, A., I. B. HARBorne, AND C. PANNELl. 1993. What parts of fleshy fruits contain secondary compounds toxic to birds and why? Biochemical Systematics and Ecology 21:421-429.

Barkett, M. D., D. C. Hil.l, J. C. Alexander, and A. 
ZITUAK. 1977. Fate of oral doses of linamarin. Canadian Journal of Physiological Pharmacology $55: 134-136$.

BASU, T. K. 1983. High-dose ascorbic acid decreases detoxification of cyanide derived from amygdalin (laetrile): Studies in guinea pigs. Canadian Journal of Physiological Pharmacology 61:14261430.

BERNAYS, E. A. 1983. Nitrogen in defense against insects. Pages 321-344 in Nitrogen as an ecological factor (J. A. Lee, S. McNeil, and I. H. Rorison, Eds.). Blackwell Scientific, Oxford.

Cirollivi, M. L., AND D. J. Levey. 1997a. Antifungal activity of Solanum fruit glycoalkaloids: Implications for frugivory and seed dispersal. Ecology 78:782-798.

Cipollini, M. L., A.ND D. J. LeVEy. 1997b. Why are some fruits toxic? Glycoalkaloids in Solanum and fruit choice by vertebrates. Ecology 78:799809.

Cipollini, M. L., AND D. J. Levey, 1997c. Secondary metabolites of fleshy vertebrate-dispersed fruits: Adaptive hypotheses and implications for seed dispersal. American Naturalist 150:346372.

Cipollini, M. L., AND E. W. Stiles. 1993. Fruit rot, antifungal defense, and palatability of fleshy fruits for frugivorous birds. Ecology 74:751-762.

Clark, L., S. S. PANKa], and J. R. Mason. 1991. Chemical repellency in birds: Relationship between chemical structure and avoidance response. Journal of Experimental Zoology 260: 310-322.

ConN, E. E. 1979. Cyanide and cyanogenic glycosides. Pages 387-412 in Herbivores: Their interaction with secondary plant metabolites (G. A. Rosenthal, and D. H. Janzen, Eds.). Academic Press, London.

DAvis, R. H. 1991. Cyanogens. Pages 202-225 in Toxic substances in crop plants (J. P. D'Mello, C. M. Duffus, and J. H. Duffus, Eds.). The Royal Society of Chemistry, Cambridge, United Kingdom.

Davis, R. H., E. A. Elzubeir, and J. S. Craston. 1988. Nutritional and biochemical factors influencing the biological effects of cyanide. Pages 219-231 in Cyanide compounds in biology (D. Evered and S. Harnett, Eds.). John Wiley and Sons, Chichester, United Kingdom.

Denslow, J. S., D. J. LeVEY, T. C. MOERMOND, AND B. C. WENTWORTH. 1987. A synthetic diet for fruiteating birds. Wilson Bulletin 99:131-134.

Ferreira, C., J. R. P. PARRA, AND W. R. Terra. 1997. The effect of dietary plant glycosides on larval midgut beta-glucosidases from Spodoptera frugiperda and Diatraea sactharalis. Insect Biochemistry and Molecular Biology 27:55-59.

FrAKES, R. A., AND R. P. SHARMA. 1986. Comparative metabolism of linamarin and amygdalin in hamsters. Food Chemistry and Toxicology 24: 417-420.

Frehner, M., M. SCalet, and E. E. Conn. 1990. Pattern of the cyanide-potential in developing fruits. Plant Physiology 94:28-34.

Glander, K. E., P. C. Wrigiti, D. E. Seigler, V. RaNDRIASOLO, AND B. RANDRIASOLO. 1989. Consumption of cyanogenic bamboo by a newly discovered species of bamboo lemur. American Journal of Primatology 19:119-124.

GLENDINNING, J. I., AND F SLANSKY. 1994. Interactions of allelochemicals with dietary constituents: Effects on deterrency. Physiological Entomology 19:173-186.

Gopol.an, V., A. Pastuszyn, W. R. Galey, and R. H. GLEW. 1992. Exolytic hydrolysis of toxic plant glucosides by guinea pig liver cytosolic beta glucosidase. Journal of Biological Chemistry 267 : 14027-14032.

Guglielmo, C. G., W. H. Karasov, AND W. J. JaKUBAS. 1996. Nutritional costs of plant secondary metabolites explain selective foraging by Ruffed Grouse. Ecology 77:1103-1115.

Herrera, C. M. 1982. Defense of ripe fruit from pests: Its significance in relation to plant-disperser interactions. American Naturalist 120 218-247.

Hruska, A. J. 1988. Cyanogenic glycosides as defense compounds: A review of the evidence Journal of Chemical Ecology 14:2213-2217.

ITO, T., AND K. KumazaWA. 1995. Precursors of antifungal substances from cherry leaves (Prunus yedonensis Matsumura). Bioscience, Biotechnology and Biochemistry 59:1944-1945.

IZAHKI, I., ANU U. N. SAFRIEL. 1989. Why are there so few exclusively trugivorous birds? Experiments on fruit digestibility. Oikos 54:23-32.

JACKSON, S., S. W. NiCIIOLSON, AND C. N. LOTZ. 1998. Sugar preferences and "side bias" in Cape Sugarbirds and Lesser Double-collared Sunbirds. Auk 115:156-165.

JANZEN, D. H. 1977. Why fruits rot, seeds mold, and meat spoils. American Naturalist 980:691-713.

JENSEN, S. R., AND B. J. NielseN. 1973. Cyanogenic glycosides in Sambucus nigra. Acta Chemica Scandinavica 27:2662-2667

Karasov, W. H. 1990. Digestion in birds: Chemical and physiological determinants and ecological implications. Studies in Avian Biology 13:391415.

LEveY, D. J., AND M. L. Cipoll.INI. 1998. A glycolakaloid in ripe fruit deters consumption by Cedar Waxwings. Auk 115:359-367.

MAJAK, W. 1991. Metabolism and absorption of toxic glycosides by ruminants. Journal of Range Management 45:67-71.

MAIAK, W. 1992. Mammalian metabolism of toxic glycoside from plants. Journal of Toxicology 11: $1-40$. 
MAIAK, W., R. E. MCDIARMID, AvD J. W. HALL. 1981 The cyanide potential of Saskatoon serviceberry (Antelanchier anifolia) and chokecherry (Prtmus irigininana). Canadian Journal of Animal Science 61:681-686.

MARTIN, A. C., H. S. ZIM, AVD A. L. Neison. 1951. American wildlife and plants: A guide to wildlife food habits. Dover Editions, New York.

Maritive DEI. Rio, C. 1994. Nutritional ecology in nectar-and fruit-eating volant vertebrates. Pages 103-127 in Food and form and function of the mammalian digestive tract (D. Chivers and P. Langer, Eds.). Cambridge University Press, Cambridge, Lnited Kingdom.

McGulin, M., C. Hobbs, R. Up'Ion, A.vid A. GoldyBERC;. 1997. Botanical safety handbook. CRC Press, Boca Raton, Florida.

Newton, G. W., E. S. Schimidi, J. P. Lewis, E. E. CONN, AND R. LAWRENCE. 1981. Amygdalin toxicity studies in rats predict chronic cyanide poisoning in man. Western Journal of Medicine 134: 97-103.

POGORZELSK1, E. 1982. Formation of cyanide as a product of decomposition of cyanogenic glycosides in the treatment of elderberry fruit ( $S_{m}$ bucus nigra). Journal of the Science of Food and Agriculture 33:496-498.

['oct.tox, J. E. 1990. Cyanogenesis in plants. Plant Physiology 94:401-405.

Poultow, I. E., AND C. P. LI. 1994. Tissue level compartmentalization of (R)-amygdalin and amygdalin hydrolase prevents large-scale cyanogenesis in undamaged Pruntts seeds. Plant Physiology 104:29-35
RAIIWAY, N. J. 1989. The Merck index: An encyclopedia of chemicals, drugs, and biologicals. Merck and Company, New York.

Rombixs, C. T. 1992. Wild life feeding and nutrition Academic Press, New York.

Swain, E., C. P. Li, A vD J. E. POUi TON. 1992. Development of the potential for cyanogenesis in maturing black cherry (Prumus serotind) fruits. Plant Physiology 98:1423-1428.

WAY, J. L. 1984. Cyanide intoxication and its mechanism of antagonism. Annual Reriew of Pharmacology and Toxicology 24:451-481.

Willson, M. F, D. A. GRAFF, AND C. J. WHELAN 1990. Color preferences of frugivorous birds in relation to the colors of fleshy truits. Journal of Avian Biology 92:545-555.

WITMER, M. C. 1996. Annual diet of Cedar Waxwings based on U.S. Biological Survey records 1885 1950) compared to diet of American Robins: Contrasts in dietary patterns and natural history. Auk 113:414-430.

WITMER, M. C. 1998. Ecological and evolutionary implications of energy and protein requirements of avian frugivores eating sugary diets. Physiological Zoology 71:599-610

WoODheAD, S., AND E. A. BERNAYS. 1978. The chemical basis of resistance of Sorghm bicolor to attack by Locusta migratoria. Entomologia Experimentalis et Applicatta 24:123-144.

Zheng, L., And J. E. Pour ion. 1995. Temporal and spatial expression of amygdalin hydrolase and mandelonitrile lyase in black cherry seeds. Plant Physiology 109:31-39.

Associate Editor: W. W. Weatiers

Reproduced with permission of the copyright owner. Further reproduction prohibited without permission. 